\title{
Who Will Stay, Who Will Leave: Decision-Making of Residents Living in Potential Hurricane Impact Areas During a Hypothetical Hurricane Event in the Rio Grande Valley
}

\author{
${ }^{1}$ Department of Sociology, University of Texas Rio Grande Valley, 1201 W University Dr., Edinburg, TX 78539, USA, E-mail: \\ dean.kyne@utrgv.edu.http://orcid.org/0000-0003-2634-519X. \\ 2 Department of Sociology, University of Texas Rio Grande Valley, Edinburg, TX 78539, USA \\ ${ }^{3}$ Department of Economics, University of Texas Rio Grande Valley, Edinburg, TX 78539, USA
}

\begin{abstract}
:
The Rio Grande Valley (RGV) has been impacted by various hurricanes throughout history. While Hurricane evacuation has been studied extensively in other contexts, there is limited systematic research on the warning and response to a large-scale severe weather event in South Texas. This study attempts to understand the evacuation decision-making behavior of Southern residents in the event of a Hurricane making landfall over the Rio Grande Valley. The study uses an online survey questionnaire with 1060 participants: 275 students attending the University of Texas-Rio Grande Valley and the remaining 785 are members of the community. Throughout the course of the study, information was gathered about selected elements: demographic characteristics, living conditions, the following and awareness of authority recommendations, decision maker roles, reasons for not wanting to leave a disaster-prone area facing an emergency, perception of a safe place, and expected help from both, governments and non-governmental organizations (NGOs) during evacuation that could impact residents' evacuation decision. Findings reveal there are a number of individuals who will remain in their place of residence, even in the deadliest of hurricane Category 5. The study provides complex factors influencing the nature of evacuation decision-making of individuals who are Hispanics living in a unique geographical location of RGV.
\end{abstract}

Keywords: evacuation decision making, Hurricane evacuation, Rio Grande Valley

DOI: $10.1515 /$ jhsem-2017-0010

\section{Introduction}

The RGV consists of four counties: Hidalgo, Cameron, Willacy, and Starr counties. It is located at the southern tip of Texas, along the Rio Grande River. As of the 2010 Census, this area hosts 1,264,291 people and has been hardhit by several hurricanes (Table 1); Hurricane Beulah in 1967 and Hurricane Dolly in 2008, which destroyed the lives and damaged the properties of thousands of people. After the landfall of Hurricane Dolly, over $\$ 2$ billion in damages was estimated, which include crops and property damage, flooding and wind (National Weather Service 2017a, 2017b).

Table 1: Hurricane History in the Rio Grande Valley.

\begin{tabular}{llll}
\hline No. & Date & Type & Severity/Impacted Areas \\
\hline 1 & $09 / 1886$ & Storm & Storm surge by Indianola Hurricane \\
& & Brownsville City \\
2 & $09 / 4-5 / 1933$ & Storm & $13-$ foot storm surge \\
& & & Cameron County - South Padre Island
\end{tabular}


3

09/20-22/1967

Hurricane Beulah

4

08/10/1980

Hurricane Allen

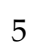

6

7

$07 / 23 / 2008$

09/16-17/1988

08/23/1999

09/12-13/2008

06/30/2010
Hurricane Gilbert

Hurricane Bret

Hurricane Dolly

Hurricane Ike

Hurricane Alex
Wind $136 \mathrm{mph}$, Busts to $109 \mathrm{mph}$, 8-14-foot storm tide 100 mph gusts in Edinburg and Pharr 18-foot tides along the Cameron/Willacy County

Flooded homes up to rooftop in Harlingen, Rio Grande Valley, Deep South Texas, South Padre Island, Port Isabel, and Boca Chica

Category 5 before entering into the Gulf, Category 3 prior to landfall

Gust $138 \mathrm{mph}$; 12-foot storm surge

Brownsville inundated with 4 feet of water

Category 3: $185 \mathrm{mph}$ wind

Storm surge flooded in Costal Cameron and Willacy County

Category 4: Gust $98 \mathrm{mph}$, Sustained winds of $73 \mathrm{mph}$

Kenedy County, Bret, Sarita, Falfurrias

Rincon Del San Jose Buoy along the Laguna Madre

The fourth most destructive Texas hurricane on record Town of South Padre Island through Laguna Vista and Port Isabel, Rio Hondo, Harlingen, and San Benito

Rainfall of 12-18 inches in Cameron, Hidalgo, Willacy, and Starr County

The storm that swallowed the Bolivar Peninsula northeast of Galveston caused severe erosion on the South Padre Island beaches 100 miles south of Brownsville

Severe flash flooding in Monterrey, Nuevo Léon, from more than 30 inches of rainfall in the foothills of the Sierra Madre Oriental

Source: (National Weather Service 2017a, 2017b).

According to the Saffir-Simpson Hurricane Wind Scale, Hurricanes in Category 3, 4, and 5 are regarded as major natural disasters with winds exceeding $111 \mathrm{mph}$. Whereas Category 1 and 2 Hurricanes, while weaker, could nevertheless still damage and cause injury to humans (National Weather Service 2017a, 2017b). In general, during hurricane events, many people are killed and injured by high-speed winds, windborne debris, storm surge, and flooding. These injuries and death rates normally occurred as a result of individuals sheltering in unsafe areas. To minimize the death and injuries caused by hurricanes, the best preventative measure is to evacuate when authorities signal evacuation warnings (FEMA 2017). In hurricane events, evacuation is highly feasible because hurricanes can be tracked several days in advance and authorities provide sufficient lead-time to evacuate.

Evacuation is the most challenging task for government agencies due to the large-scale and complex nature of the operation. In the case of hurricane events, evacuation involves transporting large and oftentimes diverse populations through the coordination of multiple governmental and non-governmental agencies. Notably, when the anticipated disaster event and its impacts are potentially catastrophic, the evacuation of people becomes essential and is a priority. For example, a day before Hurricane Matthew was categorized as a Category 4 with $140 \mathrm{mph}$ winds, and gusts up to $165 \mathrm{mph}$, authorities evacuated more than 2 million people living in Florida, Georgia, and South Carolina (which was regarded as the largest mandatory evacuation after Hurricane Sandy in 2012 in the United States) (CNN Wire 2016).

"If you are watching this (TV broadcasting) in the evacuation area, get out. Don't take a chance. Time is running out...There are no excuses. You have to leave. Evacuate, evacuate, evacuate," Florida Governor Rick Scott said in a dire warning Thursday morning (CNN Wire 2016).

Because Hurricane Matthew, a Category 4 hurricane was anticipated to have severe impacts, the President of the United States had to warn the residents-at-risk to evacuate.

"Please evacuate now. You could rebuild your homes. You could repair your home damages. However, you could not restore your life (CNN Wire 2016)."

Despite a Presidential order to evacuate the area, many nevertheless remained in their homes. Similarly, only $30 \%$ of people evacuated ahead of Hurricane Matthew (CNN Wire 2016). During the Hurricane Dolly event in 2008, state and local agencies provided warning and evacuation orders several days prior to the Hurricane landfall. However, some residents did not respond or comply with the warnings in either a timely manner or at all, and preferred to "wait and see what happen[ed]" (Ruin et al. 2008). 
While an evacuation could save lives of individuals living in at-risk areas, it is highly associated with time, money, and costs (Kolen 2016). In the past hurricane history, federal, state, and local agencies made great efforts in preparing for and evacuating the residents from the would-be-impacted areas prior to and after the hurricane; Spending millions of taxpayers' monies carrying out the evacuation and other related activities. During Hurricane Ike in 2008, evacuation efforts by state officials included the preparation of 1350 buses to evacuate residents from dangerous areas (Zucchino 2008). In the event of Hurricane Dolly in 2008, the Federal Emergency Agency (FEMA) provided more than $\$ 44$ million in aid to residents for temporary housing, home and business repairs, as well as other related costs (Ruin et al. 2008).

Among various stakeholders, local governments are responsible for the dissemination of effective risk communication, preparedness, and evacuation (Lindell, Parter, and Perry 2006). For example, 73\% of the respondents perceive the government as primarily responsible for protection against damages from flood in a study conducted in the Netherland (Terpstra and Gutteling 2008). There are studies (e.g. Terpstra, Lindell, and Gutteling 2009) that recommend government authorities to understand risk communication and how individuals' respond and make decisions to protect themselves from the potential risks in at-risk areas. Authorities gain, by understanding risk communication, utilizing the risk-related information, and making decisions to protect residents, the ability to effectively formulate strategies that are implemented into a strategic plan to communicate risk and effective evacuations for their communities.

In order to effectively develop an evacuation plan and allocate resources accordingly, understanding the evacuation decision-making process of individuals living in hurricane prone areas is essential for all federal, state, and local authorities. For instance, preparing buses to evacuate people in the potential impact areas requires reasonable estimates of how many people are likely to evacuate, an absence of which, risks too many or too few buses. Without such understanding, the allocation and utilization of resources could be ineffective, as they may be under/non utilized and/or poorly distributed.

The study area of the Rio Grande Valley consists of four counties that host more than 1.3 million people, a majority of who are Hispanic or of Latino origin; $89.4 \%, 88.1 \%, 96.3 \%$, and $91.8 \%$ of the total population in Cameron, Willacy, Starr, and Hidalgo County respectively, identify as Hispanic or Latino (Census Bureau 2010). According to the Census Bureau (2016), 32.0\%, 35.4\%, 30.9\%, and 31.1\% of the total population of these four counties are living under poverty. This specific population consists of ethnic minorities and low-incomestatus individuals, which tend to be more vulnerable during disasters (Enarson and Morrow 1997; Cutter et al. 2006; Peguero 2006; Baker and Cormier 2015). In addition, studies (e.g. Balbus and Malina 2009; Burke, Bethel, and Britt 2012) find Latinos, in particular, socially isolated migrants and seasonal farmworkers, are not prepared for a natural disaster. Factors contributing to their lack of preparation can range from language barriers, lack of knowledge of the event, financial difficulties, lack of transportation for evacuation, and the underestimation of a potential disaster event's negative impacts. In the existing literature, the studies focusing on Hispanic or Latinos are rare (e.g. Peacock, Brody, and Highfield 2005; Burke, Bethel, and Britt 2012) and there are limited studies (e.g. Thiede and Brown 2013; Huang, Lindell, and Prater 2016), which focus on evacuation decision-making of individuals during hurricane events. More specifically, there are no studies focusing on the evacuation decision-making of Rio Grande Valley residents. This area holds a wealth of knowledge in which studies are able to analyze a population of mostly Latino or Hispanic populations from diverse educational achievements, occupations, and socioeconomic statuses. To fill the gap, this study will evaluate and collect data on residents who live in the valley, whom decide to remain or leave in the event of hurricane warnings, and what effects these decisions. To do so, this study looks at various elements relating, in particular, to evacuation decision-making.

The study elements include:

1. Demographic Characteristics (gender, age, education level, household size)

2. Living Conditions (story of living, house materials, household size, and flooded area)

3. Authority Order

4. Decision Maker Role

5. Reason for Refusing Evacuation

6. Perception of "Safe Place"

7. Expected helps from Government and NGOs 


\section{Methods and Data}

The subjects of the study include individuals living in the Rio Grande Valley (RGV). To collect data, an onlinesurvey questionnaire, which consists of 14 questions, was developed. The survey questionnaire asks about the study elements surrounding the five hurricane categories based on the Saffir-Simpson Hurricane Wind Scale (FEMA 2017) (Table 2). After receiving the Internal Review Board (IRB) approval, the survey questionnaire was distributed online to students in four Introduction to Sociology classes, and individuals working in Hidalgo County. 275 of the 468 possible students completed the survey. Extra credit was provided to students for their participation and a second option was provided for those who did not want to participate. Individuals taking the survey were encouraged to forward the survey link to four of their extended family members or friends, who did not live under the same roof, but resided nearby, within the boundaries of the area included in the study. The survey period lasted from late October to the end of November 2016. There were a total of 780 community members who completed the survey. After dropping all the respondents who did not complete the entire survey questions (45) and whose zip code was outside of the valley (53), the final data set included 962 individuals living in 46 of the 57 total RGV zip codes (Table 3, Figure 1). The distribution of respondents shows a higher number of respondents in the zip code areas of Harlingen, Brownsville, Raymondville, Edinburg, McAllen, Mission, Pharr, Roma, and Rio Grande City.

Table 2: The Saffir-Simpson Hurricane Wind Scale.

\begin{tabular}{lll}
\hline Category & Sustained Winds & Types of Damage Due to Hurricane Winds \\
\hline 1 & $74-95 \mathrm{mph}$ & These very dangerous winds will produce some damage \\
2 & $96-110 \mathrm{mph}$ & These extremely dangerous winds will cause extensive damage \\
3 (major) & $111-129 \mathrm{mph}$ & Devastating damage will occur \\
4 (major) & $130-156 \mathrm{mph}$ & Catastrophic damage will occur \\
5 (major) & $157 \mathrm{mph}$ or higher & Catastrophic damage will occur \\
\hline
\end{tabular}

Source: (FEMA 2017).

Table 3: Sample and Response Rate.

\begin{tabular}{|c|c|c|c|}
\hline & Students & Community Members & Total \\
\hline Survey sample & 468 & 1100 & 1568 \\
\hline Respondents & 275 & 785 & 1060 \\
\hline Response rate & $59 \%$ & $71 \%$ & $68 \%$ \\
\hline Excluded responses & & & \\
\hline Respondents who did not complete the survey & & & -45 \\
\hline Respondents who did not live in RGV & & & -53 \\
\hline Total useable responses & & & 962 \\
\hline Actual response rate & & & $61 \%$ \\
\hline
\end{tabular}




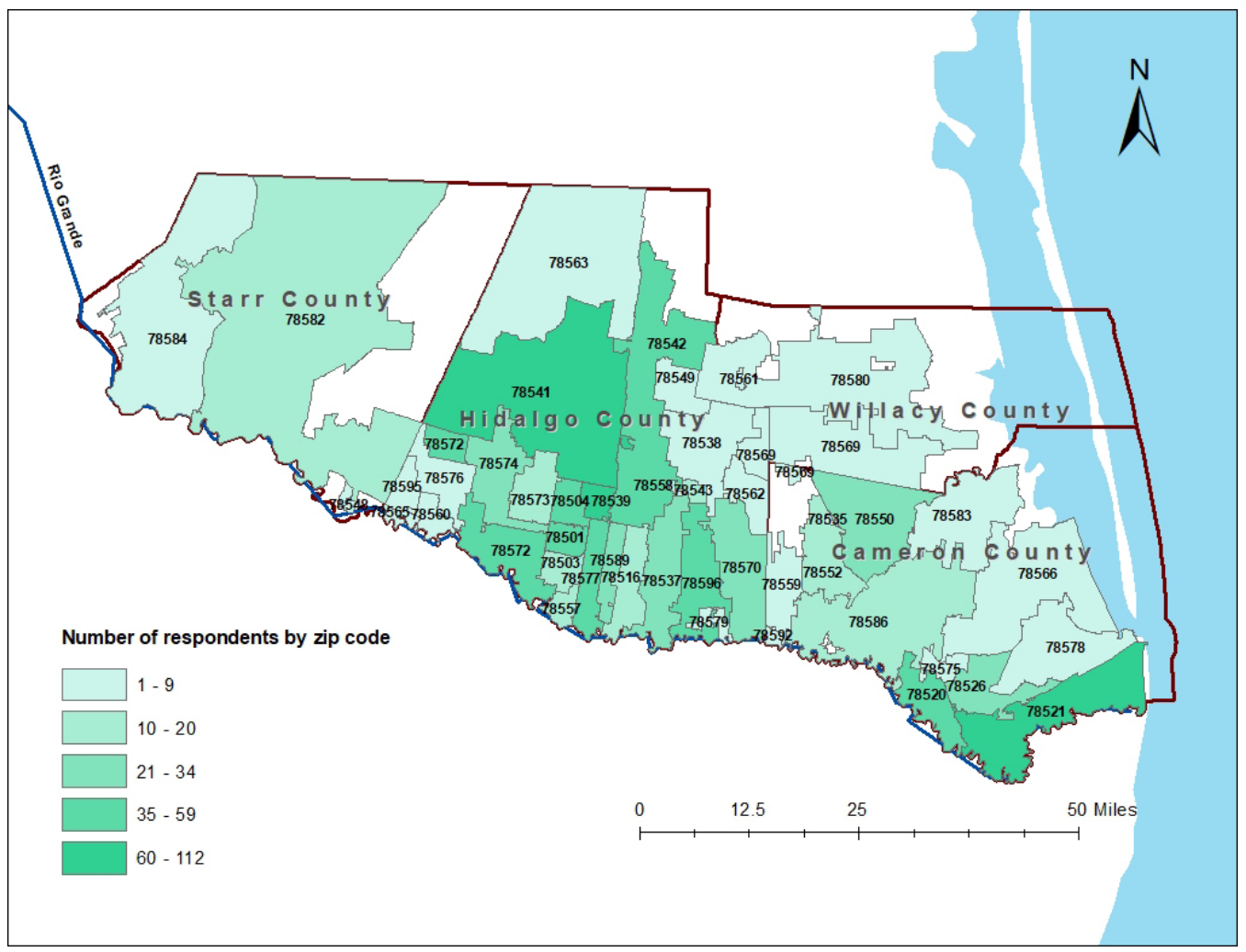

Figure 1: Number of Respondents by Zip Code in Evacuation Decision-Making Survey.

The data being exploratory in nature, should in some cases, be approached with caution. One issue relates to the generalizability of the results on two fronts. First, caution should be exercised in generalizing findings to areas beyond the Rio Grande Valley in the United States. Deep South Texas is a unique area in terms of infrastructure, demographics, and culture. Nevertheless, the data do provide interesting insights into the potential evacuation behavior of populations of South Texas, as well as, populations from poor, coastal areas. The sample is also not randomized; however, it matches population parameters on a variety of attributes. For instance, the Census Bureau (2016) reports roughly $60 \%$ of individuals over 25 years of age in the RGV hold a high school diploma.

\section{Results}

The sample included 39\% male participants and $61 \%$ females, with the majority of the respondents (67\%) being in the 18-25 years-old range, 65\% having received their high school diploma, and $15 \%$ of them graduated college/university. In terms of residence, $66 \%$ of respondents live in a single-family home and $65 \%$ live in a brick home [Appendix (Table 4)].

In the event of Hurricane Category 1 (wind speed of 74-96 mph) and Hurricane Category 2 (wind speed of 95-110 mph), overall findings show about $22 \%$ and $40 \%$ of the respondents planned to evacuate, respectively (Figure 2). In the event of major Hurricane events (Category 3, 4, and 5), 66\%, 85\%, and 91\%, respectively, reported an intention to leave the area. Specifically, for Category 3 Hurricanes, this suggests $34 \%$ of the total respondents may be expected to shelter in place. Similarly, in the event of a Category 4 or 5 Hurricane, about $14 \%$ and $8 \%$, respectively, responded they would remain in their place of residence.

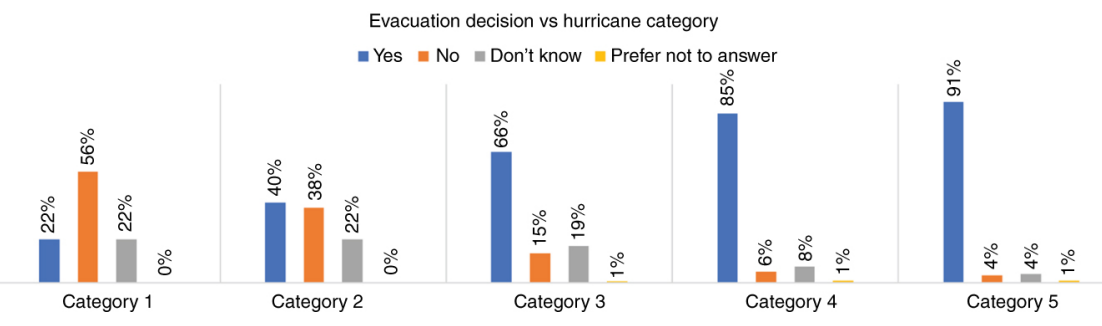

Figure 2: Evacuation Decision-Making of Residents Living in the RGV in Case of a Hurricane Event. 
Figure 3 shows spatial distribution of respondents who made the evacuation decision to leave their residence in case of a Category 5 hurricane. The findings show not all individuals want to evacuate in case of a Category 5 hurricane. What is notable about the geographic distribution of the "yes" response is the intention to evacuate seems to poorly correlate to objective risk. In the Rio Grande Valley, storms originate off the coast and make landfall in Cameron County, at which point the Hurricane is at its peak strength, diminishing in threat as it moves inland towards Hidalgo and subsequently Starr County. Unexpectedly, respondents from Cameron County appear no more or less likely than Hidalgo or Starr County residents to evacuate. In particular, this pattern remained similar across all strength categories. This evokes some concern.
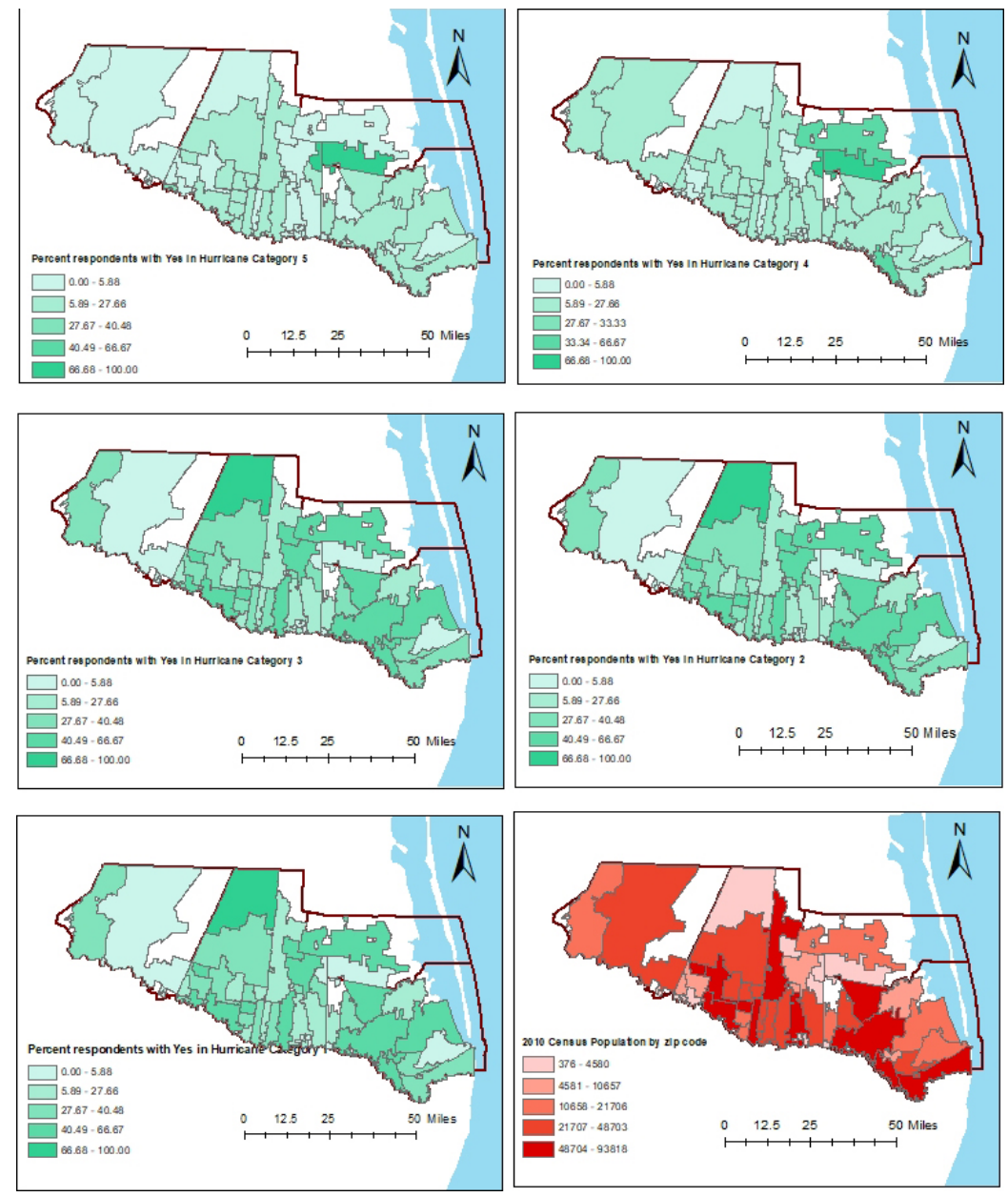

Figure 3: Spatial Distribution of the Percent of Respondents Who Would Evacuate in the Five Hurricane Categories in the Rio Grande Valley.

\subsection{Demographic Characteristics and Evacuation Decision-Making}

This study examines the relationship between demographic characteristics - namely gender, age, education level, and household size - which might influence the evacuation decision-making of individuals living in the Rio Grande Valley. First, findings on gender and evacuation decision-making reveal there is a correlation between gender and evacuation decision-making. For example, among $32 \%$ of the individuals who would evacuate, $24 \%$ of them are female, whereas $18 \%$ are male (Figure 4 ), a finding which does not surprise given females have been found more likely to evacuate in the past (Bateman and Edwards 2002) and also more likely to perceive environmental risks as higher than males (Flynn, Slovic, and Mertz 1994). Female subjects tend to show their risk-averse orientation in making evacuation decisions. It was evident among the individuals who responded "no" to evacuate; the number of females are less than the number of males. Such trends are observed across all five hurricane categories. In the case of a Category 5 Hurricane event among individuals who make a decision to leave, both genders equally avoid the risk; 91\% of males and 91\% of females say "yes" to evacuate (Figure 4). However, a higher percent of female respondents is observed in the "Don't know" category across all hurricane categories, except in a Category 5 Hurricane. The study performs a chi-square test of independence in order to investigate the association between gender and evacuation decision-making variables. The 
association is significant, $X_{2}(12)=12.9, \mathrm{p}<0.05$ and $X_{2}(12)=22.63, \mathrm{p}<0.001$ in a hypothetical Category 2 and 3 Hurricane, respectively (Figure 4).

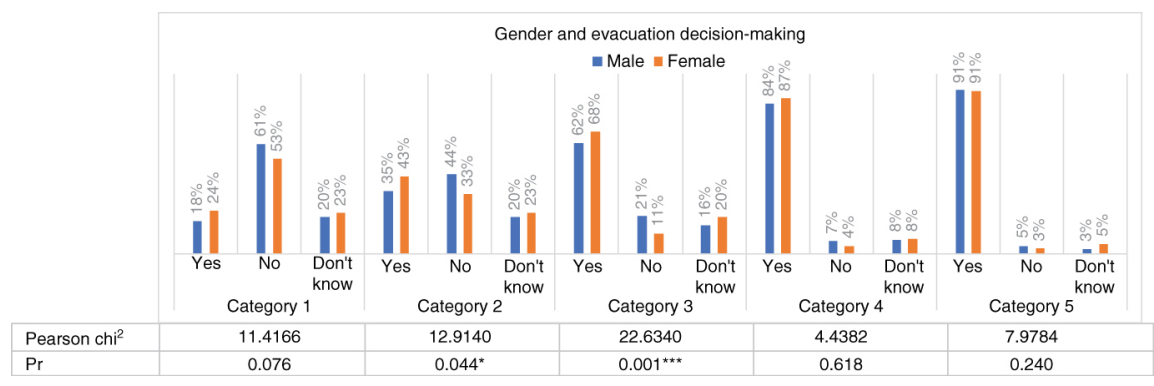

Figure 4: Gender and Evacuation Decision-Making in Case of a Hurricane Event. Note: ${ }^{*} \mathrm{p}<0.05,{ }^{* *} \mathrm{p}<0.01,{ }^{* * *} \mathrm{p}<0.001$.

There is an interesting trend between age of respondents and their evacuation decision-making. All respondents who are older than 76 years old made a decision to evacuate themselves in all five hurricane categories (Figure 5). In hurricane Category 1, findings show more individuals in all age groups tend to make a "no" evacuation decision, except in the group of 76 years of age or older. In particular, a higher percent of individuals who are under 18 years old is observed with making a decision of "no" to leave in case of Hurricane Category 1 , whereas $100 \%$ of the individuals in the same age group say to leave the areas in case of a Category 5 Hurricane. One notion is people in the age groups, 56-75 and 76 years or older, show a clear decision-making of either "yes" or "no," and they do not show a wait-and-see attitude; as none of them indicated a "don't know" answer for a Category 4 and 5 Hurricane (Figure 5). Another reason why older adults may opt to evacuate in higher numbers may relate to disaster experience; those older than 75 may have experienced more hurricanes in comparison to younger cohorts. This is significant because the literature suggests experience with disasters is likely predictive of preparedness and concern over future disasters (Motoyoshi 2006; Miceli, Sotgiu, and Settanni 2007), a finding which may serve to explain this trend. The study performs a chi-square test of independence in order to investigate the association between age and evacuation decision-making variables. The association was significant, $X_{2}(18)=31.75, \mathrm{p}<0.05, X_{2}(13)=34.95, \mathrm{p}<0.01$, and $X_{2}(13)=29.92, \mathrm{p}<0.05$ in a hypothetical Category 1, 2, and 3 Hurricane, respectively (Figure 5).

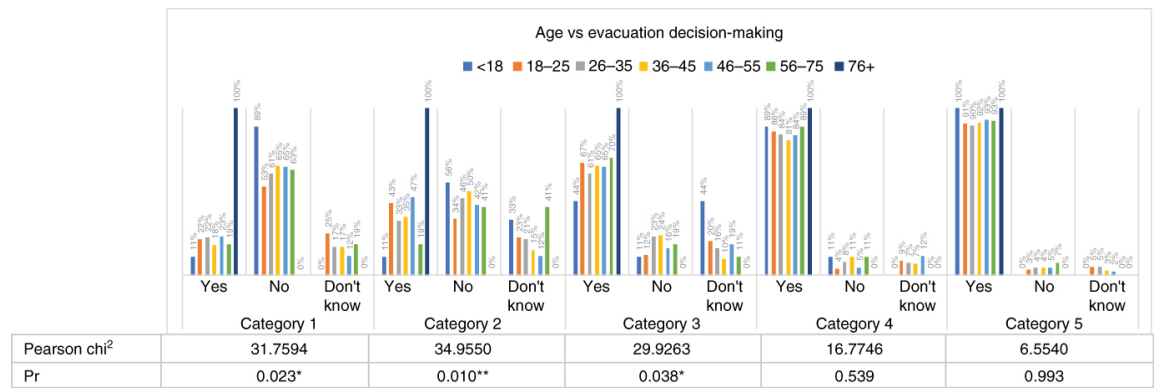

Figure 5: Age vs. Evacuation Decision-Making in Case of a Hurricane Event. Note: ${ }^{*} \mathrm{p}<0.05,{ }^{* *} \mathrm{p}<0.01,{ }^{* * *} \mathrm{p}<0.001$.

There is a notable relationship between educational level attained and the evacuation decision-making process. This study collected data on six education levels completed: some high school, high school diploma, Bachelor Degree, Graduate degree (either Masters or Ph.D.) and other (who identified themselves as individuals with associate degree, working on bachelor degree, middle school diploma, and certificate). In the case of a Category 5 Hurricane, among individuals who decide to stay, the highest percent (9\%) was found to be in the "some high school" group. In the same category, the highest percent (96\%) of individuals who decide to leave are those with graduate degrees (Figure 6). Similarly, in the Category 3, 4, and 5 Hurricane, the highest percent $(24 \%$, $13 \%$, and $9 \%$, respectively) of individuals with some high school are observed to remain. This finding confirms what is commonly seen in the literature regarding education and sheltering (e.g. Lazo et al. 2010; Hasan et al. 2011). During a tornado on March 1, 1997, in Arkansas, those with higher levels of education were observed more likely to seek shelter following a tornado warning (Balluz et al. 2000). The study performs a chi-square test of independence in order to investigate the association between level of education and evacuation decisionmaking variables. The association was not statistically significant in all five hypothetical hurricane categories (Figure 6). 


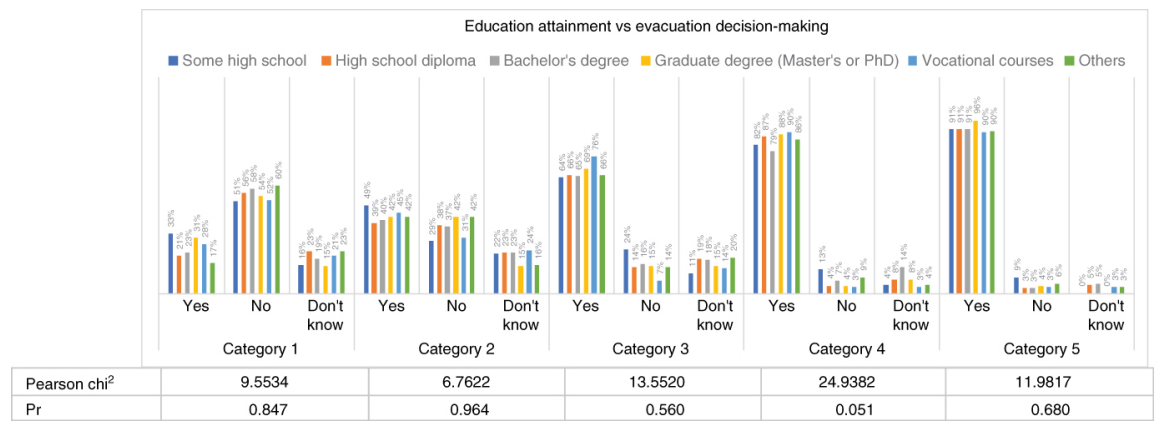

Figure 6: Education Attainment vs. Evacuation Decision-Making in Case of a Hurricane Event. Note: ${ }^{*} \mathrm{p}<0.05,{ }^{* *} \mathrm{p}<0.01,{ }^{* * *} \mathrm{p}<0.001$.

There is some evidence to suggest household size, particularly the number of children present in the household, shape decisions to evacuate (Solis, Thomas, and Letson 2010). The study examines the correlation between household size and the evacuation decision-making process. Findings demonstrate the households with the largest number of members ( 8 or more) responded they would leave before one of the major category hurricanes (Category 3, 4, and 5 Hurricanes) (Figure 7). Moving with a large number of household members might not be easy, but these families seemed to take a safer approach. However, the same respondents stated they would stay if a hurricane were identified as a Category 1 or 2 event. In the event of a Category 5 Hurricane, the households with 2-4 members are the largest percent (4\%) that would remain in their homes, followed by the households with 5-7 members (3\%) (Figure 7). Households that are made up of 1 member are the largest number of individuals that decide to stay in the events of a Category 1, 2, 3, and 4 Hurricane. It is interestingly noted that common sense would dictate households with a larger number of members ( 8 or more) might find it harder to leave. However, findings reveal they are willing to leave for the sake of their household members' safety in case of a Category 5 Hurricane. In contrast, households with one member could be perceived to have the ability to leave or evacuate themselves easily, but findings show this group tends to remain; $2 \%$ of households with 1 member say "no" and 3\% say "don't know" when responding to leaving. The study performs a chi-square test of independence in order to investigate the association between household size and evacuation decision-making variables. The association was not statistically significant in all five hypothetical hurricane categories (Figure 7). An analysis of association between the education attainment and no money indicates that respondents who do not want to leave in the hurricane Category 5 includes $13 \%$ with some high school, $12 \%$ with high school, and $10 \%$ with bachelor, and $4 \%$ with master or Ph.D. who indicated no money to evacuate. Among people who remained to stay and who had no money, $80 \%$ of them are with high school, $10 \%$ with some high school, and 10\% with bachelor.

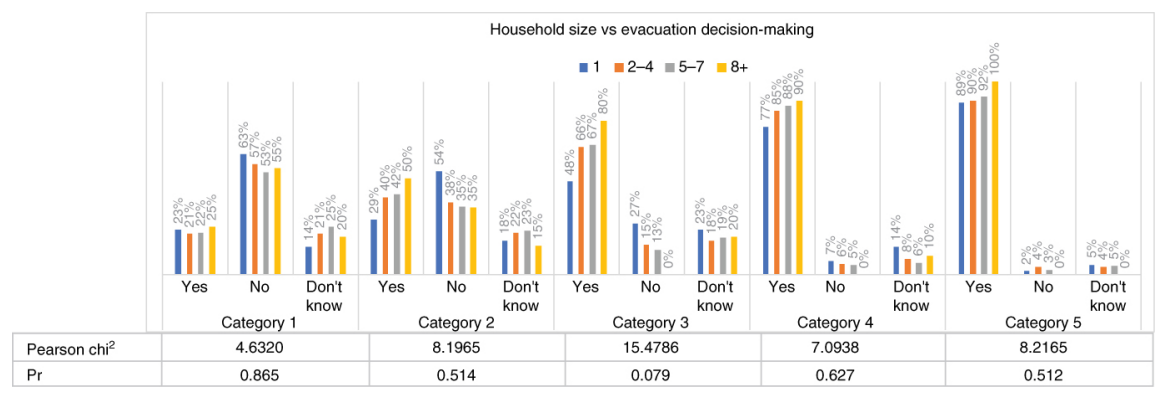

Figure 7: Household Size vs Evacuation Decision-Making in Case of a Hurricane Event.

Note: ${ }^{*} \mathrm{p}<0.05,{ }^{* *} \mathrm{p}<0.01,{ }^{* * *} \mathrm{p}<0.001$.

\subsection{Living Conditions and Evacuation Decision-Making}

The study looks into the living conditions of the respondents including house materials, the floor they live on, and flooding areas, which might influence their decision-making to evacuate. First, a house's resistance to hurricane wind would vary depending on the materials used during construction. Structural protection with different house materials may cause them to overestimate the effectiveness of the perceived risk-level associated with a potential hurricane event. When the perceived risk is low, residents are unlikely to take a self-protective action to evacuate (Harding and Parker 1974; Terpstra and Gutteling 2008; Terpstra, Lindell, and Gutteling 2009). For example, it was evident residents in New Orleans during Hurricane Katrina overestimated the effectiveness of structural protection (Terpstra and Gutteling 2008). The study gathered information on the materials of the 
house the respondents live in. There are four categories: block, brick, wood, and other. In particular for the RGV study, the "Other" category (in which 32 respondents reported to reside) includes mobile home, metal, fiber cement planks, stucco, brick and wood, aluminum, and Styrofoam. In general, block and brick houses might be more resistant to wind than wood and other types of material (Hasan et al. 2011). It was supported by the findings that a higher percent of respondents living in wood or homes built with "other" materials would like to leave across the five hurricane categories (Figure 8). Furthermore, in case of a Category 5 Hurricane event, the highest percent (94\%) of respondents living in houses built with "other" materials are observed to decide on leaving their homes. One interesting trend was observed among individuals (more than $20 \%$ of the total) living in brick homes who answered "don't know" for Category 1,2, and 3 events. It could be implied residents would like to wait-and-see how the situation develops while they feel safe in their homes made of bricks in major hurricane events (Category 3, 4, and 5 Hurricane). This is somewhat concerning, especially when considering flooding oftentimes accounts for the higher mortality rates during Hurricanes (e.g. Hurricane Katrina). Under such circumstances where major flooding occurs, brick and mortar buildings, while more resistant to the physical impacts of winds and water, offer no more or less protection from drowning in comparison to other structures. Inhabitants may be trapped by floodwaters or swept away if evacuation is delayed or decided against under the assumption of safety. The study performs a chi-square test of independence in order to investigate the association between materials of the house and evacuation decision-making variables. The association was not statistically significant in all five hypothetical hurricane categories (Figure 8).

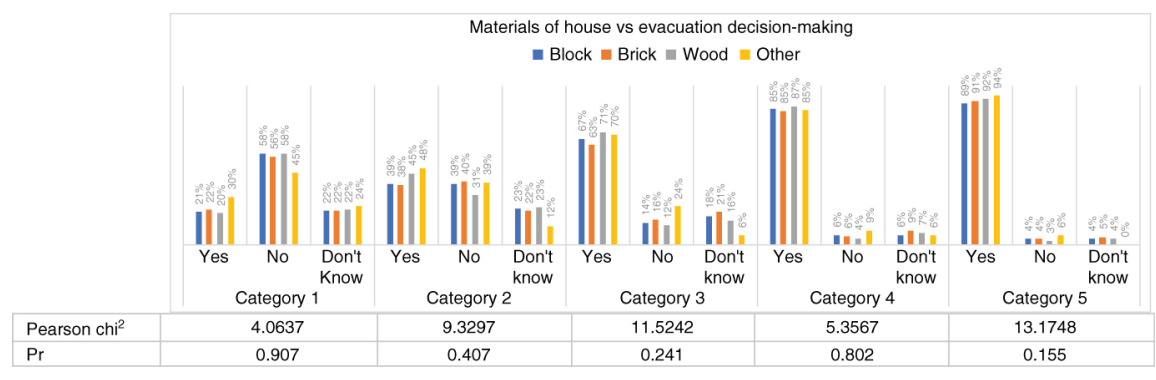

Figure 8: Materials of House vs. Evacuation Decision-Making in Case of a Hurricane Event. Note: ${ }^{*} \mathrm{p}<0.05,{ }^{* *} \mathrm{p}<0.01,{ }^{* * *} \mathrm{p}<0.001$.

In general, the severity of home damage by wind in a hurricane event might vary depending on the height of the building and the speed of the wind. All individuals living on the 3rd floor and higher demonstrated their willingness to remain in their homes in the event of a Category 1 Hurricane; however, they all decided to leave their places across the other four categories (Category 2, 3, 4, and 5) (Figure 9). Individuals living on the 3rd floor show a mix of evacuation decisions; $20 \%, 60 \%, 67 \%$, and $80 \%$ of them decided to leave in case of a Category 1, 2,3, and 4 Hurricane, respectively. The same individuals $(60 \%)$ decided to leave in case of a Category 5 Hurricane whereas the rest, $40 \%$, held a "don't know" decision. In particular, identifying individuals living on the 1st and 2nd floor are the second and third highest following individuals living on higher than the 3rd floor to demonstrate their decision to leave in case of a Category 5 Hurricane. The study performs a chi-square test of independence in order to investigate the association between floor living on and evacuation decisionmaking variables. The association was not statistically significant in all five hypothetical hurricane categories (Figure 9).

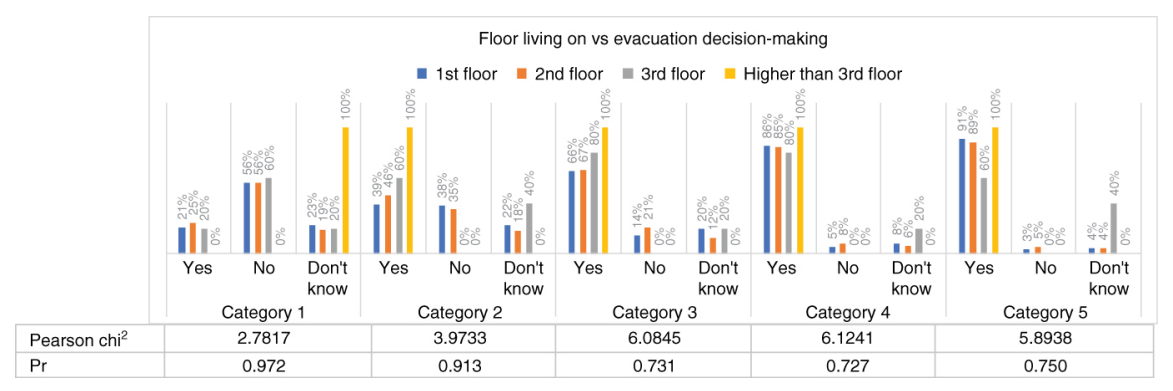

Figure 9: Floor Living on vs. Evacuation Decision-Making in Case of a Hurricane Event. Note: ${ }^{*} \mathrm{p}<0.05,{ }^{* *} \mathrm{p}<0.01,{ }^{* * *} \mathrm{p}<0.001$.

Findings indicate of those individuals living in flood-prone areas after non-hurricane rain, only $23 \%$ show their decision to leave in case of a Category 1 Hurricane. Furthermore, of this same group of individuals, 57\% would stay in their homes and the remaining $20 \%$ were not certain about their decision (Figure 10). About 20\%, $21 \%$ and $19 \%$ of individuals who live in flood areas are uncertain about their evacuation decision-making in 
Category 1, 2, and 3 Hurricanes, respectively. In case of a Category 5 hurricane, 9\% of residents who lived in a flood-prone area would stay and $4 \%$ show similar decision-making behavior in case of a Category 5 Hurricane. The majority of the individuals living in flood-prone areas, $84 \%$ and $90 \%$, would leave in a Category 4 and 5 Hurricane. The study performs a chi-square test of independence in order to investigate the association between living in a flooded area and evacuation decision-making variables. The association was not statistically significant in all five hypothetical hurricane categories (Figure 10).

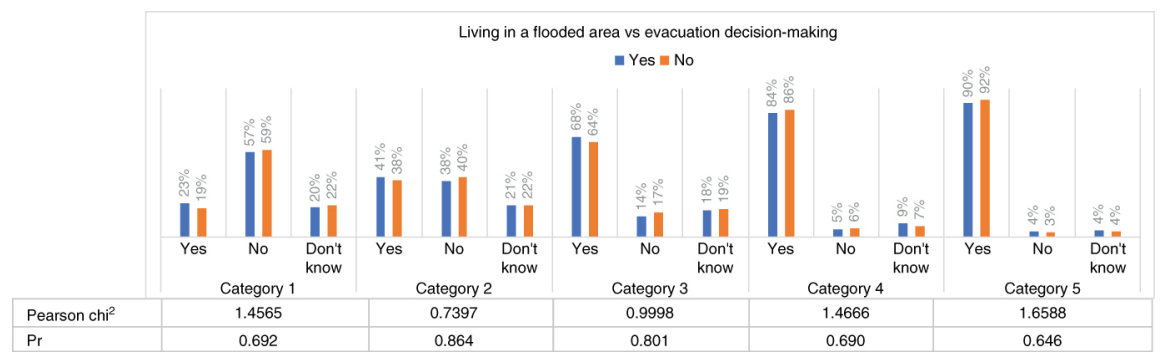

Figure 10: Living in a Flooded Area vs. Evacuation Decision-Making in Case of a Hurricane Event. Note: ${ }^{*} \mathrm{p}<0.05,{ }^{* *} \mathrm{p}<0.01,{ }^{* * *} \mathrm{p}<0.001$.

\subsection{Following Evacuation Order and Evacuation Decision-Making}

Among the individuals who would follow the authorities' evacuation orders during a hurricane event, in particular, a Category 1 Hurricane, 26\% who would make the decision to leave on their own, without the need for an order. Whereas, there were $52 \%$ who responded "no" to leaving, and $22 \%$ who were uncertain about their decision to leave (Figure 11). In the same event, $20 \%$ who made the decision not to leave would follow the evacuation orders, as well as, $18 \%$ of them who were uncertain would follow the order. Similarly, $48 \%$ of individuals who decided not to leave, 35\%,20\%, and 17\% in a Category 2, 3, 4, and 5 Hurricane, respectively, would follow the evacuation orders. In the major events, $58 \%$ of them responded they would not follow the orders, but they made the decision to evacuate on their own, in a Category 3 Hurricane, $72 \%$ in Category 4 Hurricane, and $77 \%$ in a Category 5 Hurricane.

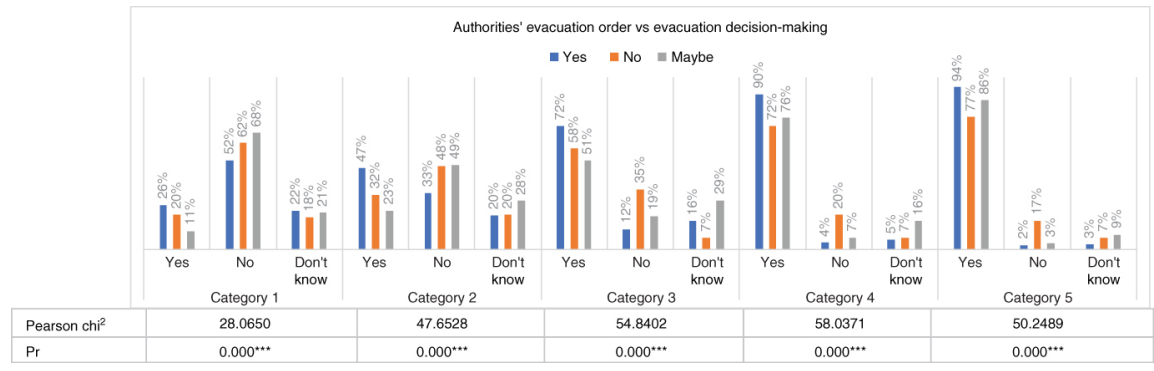

Figure 11: Authorities' Evacuation Order vs. Evacuation Decision-Making in Case of a Hurricane. Note: ${ }^{*} p<0.05,{ }^{* *} p<0.01,{ }^{* * *} p<0.001$.

In addition, individuals who were not certain to follow the evacuation order have already made up their decision to leave: $11 \%, 23 \%, 51 \%, 76 \%$, and $86 \%$ in a Category 1, 2, 3, 4, and 5 Hurricane, respectively. In other words, the authorities' evacuation order could help individuals make an evacuation decision, especially for those who either did not want to leave or were uncertain with their evacuation decision. Once they see the authorities' recommendation, they could reconsider their decision to leave their homes, which are at risk. Again, this seems to reflect prevailing trends in the empirical literature, where official warnings or warnings issued from an institution with vested authority are viewed as more credible (Perry and Greene 1983). The study performs a chi-square test of independence in order to investigate the association between authorities' evacuation order and evacuation decision-making variables. The association was significant, $X_{2}(6)=28.06, p<0.001, X_{2}(6)$ $=47.65, \mathrm{p}<0.001, X_{2}(6)=54.84, \mathrm{p}<0.001, X_{2}(6)=58.03, \mathrm{p}<0.001$, and $X_{2}(6)=50.24, \mathrm{p}<0.001$ in a hypothetical Category 1, 2, 3, 4, and 5 Hurricane, respectively (Figure 11).

The study further investigates to what extent authorities' recommendations might influence the evacuation decision. The study would like to find out if residents make decision based on their own judgment or if others influence it: friends, family members, and authorities. The survey collected five judgments to base on, namely (1) authority recommendation, (2) your own judgment, (3) family recommendation, (4) friend recommendation, and (5) others. There were six respondents who indicated, others, in which they explain their judgment 
as a combination of the first three, a combination of all, a combination of my partner's and mine, and so on. In case of a Category 5 Hurricane, findings show authority recommendation, your own judgment, family recommendation, and other are almost equally important. The friend recommendation is observed as holding the least influence on evacuation decision-making. A similar trend of friend recommendation is also observed in the other major hurricane categories ( 3 and 4). It is interestingly to note authority recommendation is more influential in a Category 4 and 5 Hurricane than the remaining lower categories. The study performs a chi-square test of independence in order to investigate the association between judgment to be based on and evacuation decision-making variables. The association was significant, $X_{2}(12)=93.52, \mathrm{p}<0.001, X_{2}(12)=98.66, \mathrm{p}<0.001$, $X_{2}(12)=63.78, p<0.001, X_{2}(12)=38.89, p<0.001$, and $X_{2}(12)=38.49, p<0.001$ in a hypothetical Category 1 , 2, 3, 4, and 5 Hurricane, respectively (Figure 12).

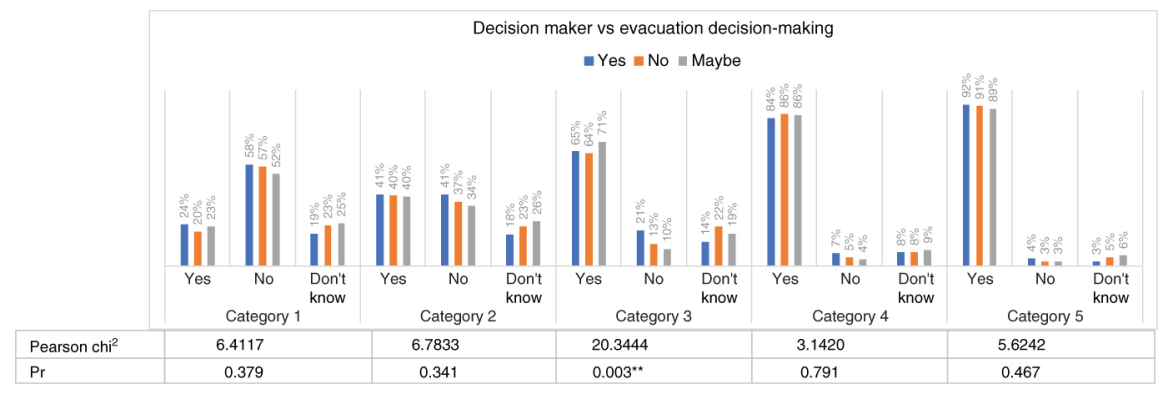

Figure 12: Based on Judgment vs Evacuation Decision-Making in Case of a Hurricane Event. Note: ${ }^{*} \mathrm{p}<0.05,{ }^{* *} \mathrm{p}<0.01,{ }^{* * *} \mathrm{p}<0.001$.

\subsection{Decision Maker Role and Evacuation Decision-Making}

Individuals who are not head decision makers for their families show their decision to evacuate from their homes in all the hurricane categories. For these individuals who are not head decision makers, $20 \%$ of them would leave in a Category 1 Hurricane, $40 \%$ for a Category 2, 64\% for a Category 3, 86\% for a Category 4 , and $91 \%$ for a Category 5 Hurricane (Figure 13). In other words, the non-decision makers show their evacuation decision-making trends follow similar trends to those who are currently heading these family roles. In case of major hurricane events, $71 \%, 86 \%$, and $89 \%$ of individuals who are uncertain about their decision maker role would go ahead and make a decision to leave in a Category 3, 4, and 5 Hurricane, respectively. In short, the findings reveal that no matter the role of the individual in the decision-making process of their household, all opted to leave. The study performs a chi-square test of independence in order to investigate the association between decision maker and evacuation decision-making variables. The association was significant, $X_{2}(6)=$ 20.34, $\mathrm{p}<0.01$ in a hypothetical Category 3 Hurricane (Figure 13).

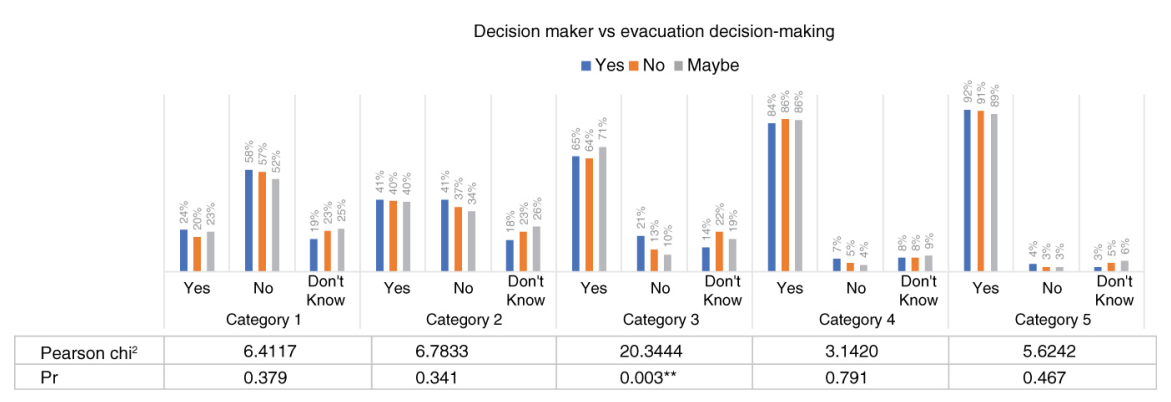

Figure 13: Decision Maker vs. Evacuation Decision-Making in Case of a Hurricane Event.

Note: ${ }^{*} \mathrm{p}<0.05,{ }^{* *} \mathrm{p}<0.01,{ }^{* * *} \mathrm{p}<0.001$.

\subsection{Reason Not Wanting to Leave and Evacuation Decision-Making}

The study collected information from the respondents to identify the reasons for not wanting to leave in case of a hurricane event. The survey collected seven reasons for not wanting to leave: (1) having pet(s) that cannot travel or I do not want to leave alone, (2) having no place to go, (3) having no money to leave, (4) not wanting to leave belongings, (5) having no friends and/or relatives living in places outside of the evacuation zone, (6) having elders who would or could not travel, and (7) having family which is unable to travel due to a disability or medical condition. $6 \%$ of the total individuals who have pets and did not want to travel made decision as 
"don't know," and 4\% of them selected a decision of "no" (Figure 14). The study performs a chi-square test of independence in order to investigate the association between reason not wanting to leave and "No" evacuating decision-making variables. The association was not statistically significant in all five hypothetical hurricane categories (Figure 14).

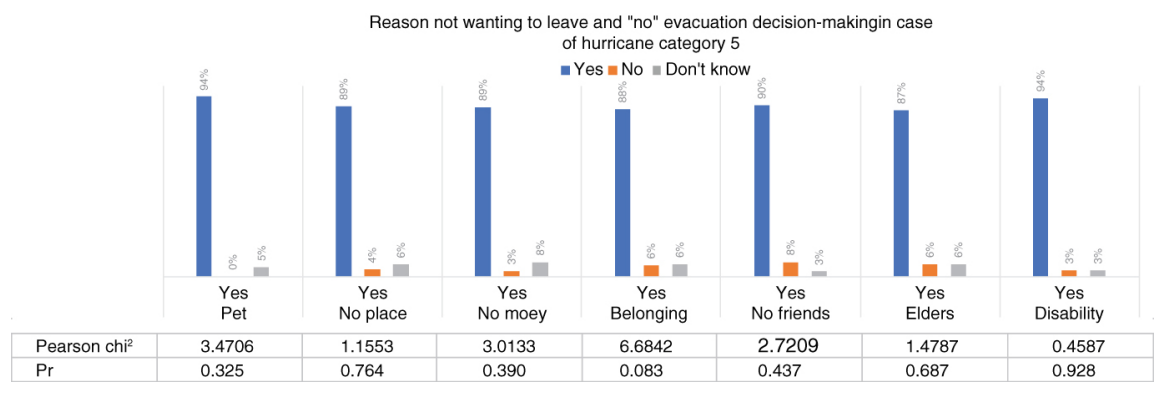

Figure 14: Reason not Wanting to Leave vs. Evacuation Decision-Making with "No" in Case of a Hurricane Event. Note: ${ }^{*} \mathrm{p}<0.05,{ }^{* *} \mathrm{p}<0.01,{ }^{* * *} \mathrm{p}<0.001$.

\subsection{Perceived Safe Place and Evacuation Decision-Making}

The survey collected responses for identified safe places where respondents would go. The choices include a safe place within the RGV, a place outside of the RGV, a place outside of Texas, a place outside of the USA, and other places. Many of the 16 respondents provided their safe place as the places that are off the hurricane pathway. Some of them mentioned a safe location would be discussed with their family members when the hurricane event takes place. One person believed their home is a safe place and would not evacuate. A higher percentage of individuals with "other" places, as a safe place, showed "yes" for evacuation decision-making than their counterparts with other ideal safe places in the event of a major Category Hurricane $(3,4$, and 5$)$ (Figure 15). It was estimated evacuation costs could exceed one million USD per coastal mile in an event of a hurricane in the US (Kolen and Helsloot 2014). The study performs a chi-square test of independence in order to investigate the association between safe place and evacuation decision-making variables. The association was not statistically significant in all five hypothetical hurricane categories (Figure 15). It is also important to note authorities could estimate the cost of transporting evacuees depending on the places the residents would be moved to.

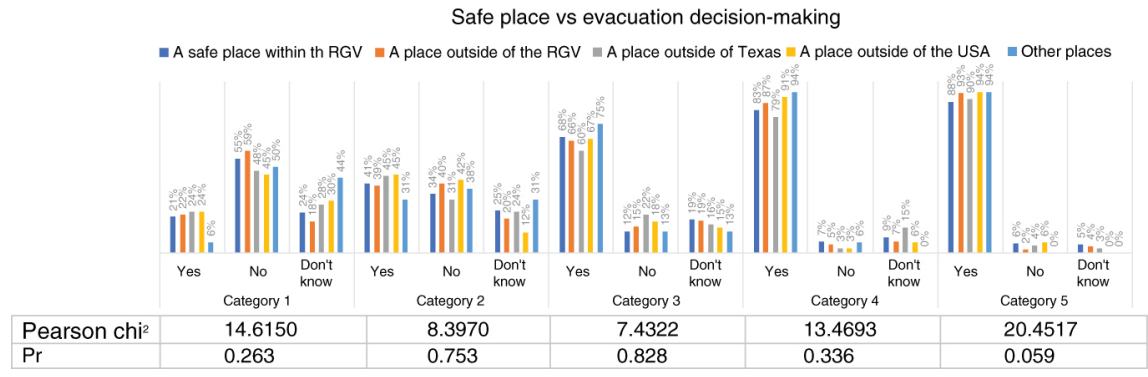

Figure 15: Safe Place vs. Evacuation Decision-Making in Case of a Hurricane Event. Note: ${ }^{*} \mathrm{p}<0.05,{ }^{* *} \mathrm{p}<0.01,{ }^{* * *} \mathrm{p}<0.001$.

\subsection{Expected Help from Government Agencies and NCOs}

Findings indicate respondents show higher expectation of help from government agencies than NGOs in case of a hurricane event (Figure 16). For example, 25\% expect public transportation services from NGOs, while $45 \%$ expect the same service from a government agency. A similar trend is observed across all other needs, except in clothing needs. Respondents have higher expectations from NGOs in meeting their need for clothing in a hurricane event. The highest percent of individuals (81\% and $81 \%)$ expect temporary shelter and drinking water from a government agency respectively, which is followed by $75 \%$ of individuals who expect food supplies from the government. Similarly, the highest percent of individuals (67\% and $64 \%)$ expect food and temporary shelter, respectively. The least needed items are sand bag for the area. The study performs a $t$-test between expected help from NGOs and the government agencies in eight kinds of assistance (Figure 16). Respondents expecting public transportation from the government agencies are greater $(M=0.45, S D=0.49)$ than 
those expecting public transportation from the NGOs $(\mathrm{M}=0.25, \mathrm{SD}=0.43), \mathrm{t}=9.6561, \mathrm{p}=0.000$ (Figure 16). Respondents expected more from NGOs in only two main materials: namely, clothes and sand bags. The findings support those of Terpstra and Gutteling (2008) in which 73\% of the total respondents regard the government as being primarily responsible for assistance. However, it should be noted providing a survey with different wording choices could result in a different set of answers selected by respondents (Helsloot and Schmidt 2012). In addition, it is imperative to note that key stakeholders including invidiuals must take serious responsibilities to effectively manage the disasters. The indivdiuals are, first and foremost, tasked with the responsiblities to prepare for emergency and disaster events followed by family, community, state, and federal governments (PHEgov 2011).

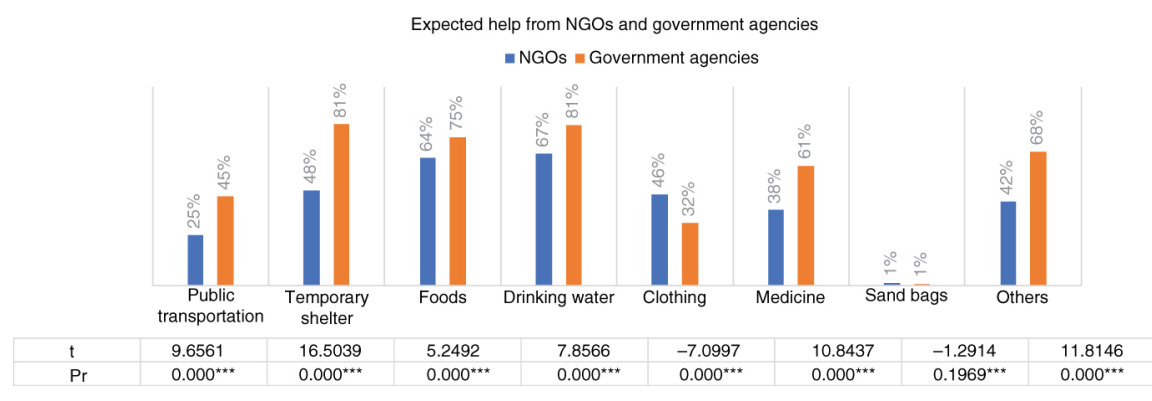

Figure 16: Expected Help from NGOs and Government Agencies. Note: ${ }^{*} \mathrm{p}<0.05,{ }^{* *} \mathrm{p}<0.01,{ }^{* * *} \mathrm{p}<0.001$.

\section{Discussion and Conclusion}

The study investigates several selected elements that might influence evacuation decision-making behavior of individuals who live in the Rio Grande Valley in the event of a hurricane. Overall, and perhaps not unexpectedly, it is found that very few of the respondents $(20 \%)$ would evacuate themselves in case of a Category 1 Hurricane. However, in the event of a major Category 3 event, only $66 \%$ of the respondents would make the decision to leave. The study further looks into the selected elements and their possible relation with the evacuation decision-making.

Any possible relationship between the demographic characteristics and evacuation decision-making behavior was examined. First, in the worst hurricane event, a Category 5, both genders tend to make the evacuation decisions with similar results. However, when it comes to a Category 1 or 2 Hurricane, results show they tend to exhibit their risk-averse orientation. Second, older adults who are 76 years or older tend to disclose a strong preference for evacuation across all potential hurricane categories. Third, individuals with low levels of education attainment appear more likely to shelter in place, whereas their counterparts with graduate degrees (either masters' or Ph.D.) appear to favor evacuation. Fourth, a logical assumption was that the greater the size of household, the more difficult for them to move out of their place; this logical assumption was not supported by the findings. In fact, all the individuals in a household size of 8 or more members show their willingness to leave in the major hurricane events: 3,4 , and 5. However, many of them tend to remain in the event of a Category 1 and 2 Hurricane.

The study also investigates any living conditions that might have an impact on evacuation decision-making behavior. First, among four different types of house materials, namely block, brick, wood, and other (a mixture of the other three materials, aluminum, and mobile homes), a higher percent of individuals living in houses made of wood show a decision to leave across all hurricane categories. In the event of a Category 1 and 2 Hurricane, individuals living in houses made of bricks demonstrated their confidence as a higher percent of them selected they did not want to leave. Second, those living higher than the 3rd floor, selected they would not stay in their homes in terms of a Category 2, 3, 4, and 5 Hurricane. However, they seem confident to stay in the event of a Category 1 Hurricane. In contrast, individuals living on the 3rd floor showed a mixture of evacuation decisions. In particular, $40 \%$ of the total individuals living on the 3rd floor surprisingly stated they might want to remain in the deadliest hurricane event a Category 5. Third, individuals living in flood-prone areas show their concerns during the major hurricane events $(3,4$, and 5$)$, whereas they were not as concerned with flooding during the event of a Category 1 and 2 Hurricane. This study's findings support the findings of some studies (Harding and Parker 1974; Terpstra and Gutteling 2008; Terpstra, Lindell, and Gutteling 2009) reflecting respondents' belief of secure structural protection causes an overestimation of effectiveness of the protection of their houses; contributing to low perceived risks leading to a "no" evacuation decision. This means 
residents, believing their homes are structurally sound, would decide, based on this idea, that they did not have to evacuate in case of a low category hurricane event.

The findings are useful for policymakers. Days before hurricanes make landfall, authorities provide information on the pathway of any given hurricane, as well as its projected strength and impact. The majority of respondents, who make a "yes" evacuation decision, showed they would follow evacuation orders. Similarly, an evacuation order could also be the deciding factor in changing an individual's decision from a previously selected "no" to a "yes" evacuation. Second, authority recommendations are very helpful for many who rely on the order(s) to make a final evacuation decision in the event of a major hurricane. Moreover, individuals' friend recommendations were not identified as influential as respondents' family recommendations or their own judgment across all five hurricane categories. Finally, findings offer guidance on which groups may require additional persuasion or assistance with respect to evacuation. For instance, since lower education is, all else equal, correlated with poverty, authorities may need to devote additional resources to areas where there are lower education levels. In the same vein, additional or alternative means of communicating information may assist those with a lower education level assess the severity of the situation differently and become aware of the varying assistance available throughout each of the hurricane categories as they present themselves.

Individuals who make an evacuation decision, either to evacuate or to remain, exhibit at least one of the seven reasons for not wanting to leave. The reason with the highest percent of mention was "having no friends." It is interesting to note, as discussed earlier, friend recommendations are the least influential to make a judgment to move. In contrast, to move out from their home during the hurricane events, the respondents need their friends' accommodation. Another factor is a lack of financial resources. Among those who are uncertain about their evacuation decision, their uncertainty stemmed from a lack of financial resources. The study's findings reflect the Census Bureau (2016) demographics of the area; the majority of the population is low-income families that lack basic resources. In addition, this study's findings support Verroen, Gutteling, and Vries (2013) findings, which determine during a disaster event, feedback in risk communication from peers (including family and friends) is important and critical.

The finding, that individuals who are most likely to be in the direct path of the strongest stage of a potential hurricane show a choice not to evacuate, is cause for concern. Further investigation should explore why individuals living closer to the coast appear no more or less likely than those inland to evacuate. Is this because individuals on the coast are no more or less informed about Hurricanes than those in Hidalgo and Starr County? Has complacency become widespread in light of so few Hurricanes striking the area? Are there some circumstances the population faces, which make them simply less likely to evacuate? These questions need to be addressed.

During a hurricane event, a safe place to refuge might vary on how individuals perceive what constitutes as a safe place for each one of the hurricane categories. Some respondents could have a perception of a safe place as a place that family members agree upon, a place that was off the hurricane track, their current home, and so on. Others may view it in terms of location such as a place within the RGV, a place outside of the RGV, a place outside of Texas or a place outside of the USA. The authorities could utilize the study's findings to developing a plan for evacuation, as well as to estimate costs for transporting residents from their living areas to the designated safe places. It was estimated that evacuation costs could exceed one million USD per coastal mile in the event of a hurricane in the US (Kolen and Helsloot 2014). Furthermore, which resources would be available for the refuge area and the time after would reflect on another investigation. From the survey, respondents specify needs from both, government and NGOs. It was evident respondents held different expectations for each, but more so from the government than NGOs. The study's findings support the findings of Terpstra and Gutteling (2008) and Terpstra, Lindell, and Gutteling (2009) in which the majority of respondents believe the government is primarily responsible for protection.

From this exploratory study, some conclusions could be made in the context of evacuation decision-making of those individuals who live in the RGV in the event of a hurricane. First, it could be anticipated that all residents living in the RGV would not evacuate themselves in the event of hurricane, and there would be some individuals who will remain during the hurricane event. Second, the evacuation decision-making is complex, as there are many elements that could potentially influence the decision-making of the residents. Third, demographic characteristics such as gender, age, educational level, and household size demonstrate a relationship with evacuation decision-making. Fourth, the government authorities' recommendation is helpful and many respondents show a willingness to follow the recommendation, even those who made decisions either not to leave or uncertain with their decision. Fifth, there are certain limitations and reasons for individuals to evacuate. Lack of financial resources and a lack of friends are the most pressing reasons for not wanting to leave. Sixth, different individuals perceive a safe place differently. There are predefined safe places for many of the respondents, but for others, identifying a safe place could come until after the track of the hurricane has been determined, a location off the hurricane track is identified, and within the family means. Seventh, residents in the RGV expect help from both, government agencies and NGOs. 
Four implications for hurricane preparedness could be made from the findings of the study. The local and state authorities could incorporate findings to a hurricane plan. First, authorities' recommendations are helpful and must prepare evacuation recommendations closely together with the National Weather Services. Second, the weather information could be used to identify a list of safe places for residents to seek shelter; keeping in mind, some may have already identified their ideal safe places. Third, both government authorities and NGOs must prepare and announce, in lay language, various types of assistance, such as transportation, foods, clothing, etc., that residents might need/expect during an evacuation. Fourth, authorities must also prepare an evacuation plan for those who live on the $3^{\text {rd }}$ floor and others whom exhibited non-evacuation decision-making during the deadliest hurricane event, a Category 5 . This study suggests future studies should investigate any possible association between education attainment and financial resources to evacuate, and their implication for evacuation planning.

Above all, the study's findings provide useful information for stakeholders including local, state, and federal governments; as well as, NGOs to have a deterministic evacuation plan. However, evacuation has many facets including accounting for uncertainties such as, forecasts, resident responses, and capacity of critical infrastructure in the decision-making process in the RGV. A probabilistic evacuation planning style is more preferable to take into account the uncertainties associated with the evacuation decision-making process (Kolen and Helsloot 2014). Above all, individuals must understand their responsibilities to actively participate in disaster preparedness, whereas the government officials should provide proper education. Education is the key to improving individual preparedness (e.g. McNeill et al. 2016).

\section{Acknowledgments}

The authors would like to thank all participants in the survey including students and their extended family members and friends, Hidalgo County employees who participated in the survey. Special thanks go to Mr. Ricardo Saldaña, Hildago County Emergency Manager.

Authors' Contribution: Dean Kyne develops survey questionnaire, conducts online survey, collects data, carries out data analyzes and GIS analyses, creates visualizations, interprets the findings and compiles the manuscript. Arlett Sophia Lomeli translates the survey questionnaire into Spanish, collects data, and edits the manuscript. William Donner interprets the findings and complies the manuscripts. Erika Zuloaga assists in conducting literature search and helps the authors in collecting data during the research study period.

Conflicts of Interest: The authors declare no conflict of interest.

\section{Appendix}

Table 4: Summary Descriptive Statistics.

\begin{tabular}{|c|c|c|c|}
\hline & Frequency & Percent & Cumulative \\
\hline \multicolumn{4}{|l|}{ Gender } \\
\hline Male & 373.00 & 38.89 & 38.89 \\
\hline Female & 583.00 & 60.79 & 99.69 \\
\hline Others & 3.00 & 0.31 & 100.00 \\
\hline Total & 959.00 & 100.00 & \\
\hline \multicolumn{4}{|l|}{ Age } \\
\hline Under 18 & 9.00 & 0.94 & 0.94 \\
\hline $18-25$ & 642.00 & 66.74 & 67.67 \\
\hline $26-35$ & 165.00 & 17.15 & 84.82 \\
\hline $36-45$ & 72.00 & 7.48 & 92.31 \\
\hline $46-55$ & 43.00 & 4.47 & 96.78 \\
\hline $56-75$ & 27.00 & 2.81 & 99.58 \\
\hline $76+$ & 4.00 & 0.42 & 100.00 \\
\hline
\end{tabular}




\begin{tabular}{lrrr}
\hline Education level & & & \\
\hline Some high school & 45.00 & 4.70 & 4.70 \\
High school diploma & 622.00 & 64.93 & 69.62 \\
Bachelor's degree & 146.00 & 15.24 & 84.86 \\
Graduate degree (Master's and/or PhD) & 26.00 & 2.71 & 87.58 \\
Vocational courses & 29.00 & 3.03 & 90.61 \\
Other (please explain) & 90.00 & 9.39 & 100.00 \\
& & & \\
\hline
\end{tabular}

\begin{tabular}{|c|c|c|c|}
\hline \multicolumn{4}{|l|}{ House type } \\
\hline One-story apartment & 116.00 & 12.07 & 12.07 \\
\hline Two-story or higher apartment complex & 93.00 & 9.68 & 21.75 \\
\hline Duplex & 22.00 & 2.29 & 24.04 \\
\hline Mobile home & 42.00 & 4.37 & 28.41 \\
\hline Prefabricated wood home & 29.00 & 3.02 & 31.43 \\
\hline Other (please explain) & 27.00 & 2.81 & 34.24 \\
\hline Single family home & 632.00 & 65.76 & 100.00 \\
\hline Total & 961.00 & 100.00 & \\
\hline \multicolumn{4}{|l|}{ House materials } \\
\hline Block & 158.00 & 16.48 & 16.48 \\
\hline Brick & 538.00 & 56.10 & 72.58 \\
\hline Wood & 230.00 & 23.98 & 96.56 \\
\hline Others & 33.00 & 3.44 & 100.00 \\
\hline Total & 959.00 & 100.00 & \\
\hline
\end{tabular}

\section{References}

Baker, Lisa R., and Loretta A. Cormier. 2015. Disasters and Vulnerable Populations: Evidence-Based Practice for the Helping Professions. New York: Springer Publishing Company.

Balbus, John M., and Catherine Malina. 2009. "Identifying Vulnerable Subpopulations for Climate Change Health Effects in the United States." Journal of Occupational and Environmental Medicine 51: 33-37.

Balluz, Lina, Laura Schieve, Talmage Holmes, Stephanie Kiezak, and Josephine Malilay. 2000. “Predictors for People's Response to a Tornado Warning, Arkansas, 1 March, 1997." Disasters 24: 71-77.

Bateman, Julie M., and Bob Edwards. 2002. "Cender and Evacuation: A Closer Look at Why Women are More Likely to Evacuate for Hurricanes." Natural Hazards Review 3: 107-117.

Burke, Sloane, Jeffrey W. Bethel, and Amber Foreman Britt. 2012. "Assessing Disaster Preparedness among Latino Migrant and Seasonal Farmworkers in Eastern North Carolina." International Journal of Environmental Research and Public Health 9 (9): 3115-3133.

Census Bureau. 2010. “QuickFacts.” https://www.census.gov/quickfacts/fact/table/US/PST045217.

Census Bureau. 2016. “QuickFacts.” Accessed https://www.census.gov/quickfacts/fact/table/cameroncountytexas,willacycountytexas,star rcountytexas, hidalgocountytexas/POP060210.

CNN Wire. 2016. This Storm Will Kill You,' FL Gov. Warns ahead of Hurricane Matthew. http://wnep.com/2016/10/06/this-storm-will-kill-you-flgov-warns-ahead-of-hurricane-matthew/.

Cutter, Susan L., Christopher T. Emrich, Jerry T. Mitchell, Bryan J. Boruff, Melanie Gall, Mathew C. Schmidtlein, Christopher G. Burton, and Cinni Melton. 2006. “The Long Road Home: Race, Class, and Recovery from Hurricane Katrina.” Environment 48: 8-20.

Enarson, Elaine, and Betty Hearn Morrow. 1997. "A Gendered Perspective: The Voices of Women." In Hurricane Andrew: Ethnicity, Cender and the Sociology of Disaster, edited by Walter Cillis Peacock, Hugh Cladwin, and Betty Hearn Morrow, 116-140. New York: Routledge.

FEMA. 2017. "How to Prepare for a Hurricane." https://www.fema.gov/media-library/assets/documents/98105.

Flynn, James, Paul Slovic, and C. K. Mertz. 1994. “Cender, Race, and Perception of Environmental Health Risks.” Risk Analysis 14 (6): $1101-1108$.

Harding, Donald M., and Dennis ]. Parker. 1974. "Flood Hazard at Shrewsbury in the UK." In Natural Hazards: Local, National, and Clobal, edited by Cilbert White, 43-52. New York: Oxford University Press.

Hasan, Samiul, Satish Ukkusuri, Hugh Cladwin, and Pamela Murray-Tuite. 2011. “Behavioral Model to Understand Household-Level Hurricane Evacuation Decision Making." Journal of Transportation Engineering-Asce 137 (5): 341-348. 
Helsloot, Ira, and Arjen Schmidt. 2012. "The Intractable Citizen and the Single-Minded Risk Expert - Mechanisms Causing the Risk Regulation Reflex Pointed Out in the Dutch Risk and Responsibility Programme." European Journal of Risk Regulation 3 (3): 305-312.

Huang, Shih-Kai, Michael K. Lindell, and Carla S. Prater. 2016. "Who Leaves and Who Stays? A Review and Statistical Meta-analysis of Hurricane Evacuation Studies." Environment and Behavior 48 (8): 991-1029.

Kolen, Bas, and Ira Helsloot. 2014. “Decision-Making and Evacuation Planning for Flood Risk Management in the Netherlands." Disasters 38 (3): 610-635.

Kolen, Bas. 2016. "Risk Based Decision Making for Evacuation in an Uncertain World." In 3rd European Conference on Flood Risk Management 7, Cedex A: EDP Sciences. https://www.e3s-conferences.org/articles/e3sconf/.../e3sconf_flood2016_19001.html.

Lazo, Jeffrey K., Donald M. Waldman, Betty H. Morrow, and Jennifer A. Thacher. 2010. “Household Evacuation Decision Making and the Benefits of Improved Hurricane Forecasting: Developing a Framework for Assessment." Weather and Forecasting 25 (1): $207-219$.

Lindell, Michael K., Carla S. Parter, and Ronald W. Perry. 2006. Fundamentals of Emergency Management. Denver, MA: John Wiley \& Sons Inc.

McNeill, Charleen C., Danita Alfred, Beth Mastel-Smith, Rebecca Fountain, and Jonathan MacClements. 2016. “Changes in Self-Reported Household Preparedness Levels Among a Rural Population After Exposure to Emergency Preparedness Campaign Materials." Journal of Homeland Security and Emergency Management 13 (1): 113-135.

Miceli, Renato, Igor Sotgiu, and Michele Settanni. 2007. “Disaster Preparedness and Perception of Flood Risk: A Study in an Alpine Valley in Italy." Journal of Environmental Psychology 28: 164-173.

Motoyoshi, Tadahiro. 2006. "Public Perception of Flood Risk and Community-Based Disaster Preparedness." In A Better Integrated Management of Disaster Risks: Toward Resilient society to Emerging Disaster Risks in Mega-Cities, edited by Saburo Ikeda, Teruki Fukuzono, and Teruko Sato, 121-134. TERRAPUB and NIED. http://www.terrapub.co.jp/e-library/nied/.

National Weather Service. 2017a. “Hurricane Preparedness, Rio Grande Valley: Hurricane History." https://www.weather.gov/bro/hurrprep_history.

National Weather Service. 2017b. “Storm Report on Hurricane Dolly in the Rio Grande Valley and Deep South Texas: Update \#2." https://www.weather.gov/bro/2008event_dollyreport.

Peacock, Walter Gillis, Samuel David Brody, and Wes Highfield. 2005. “Hurricane Risk Perceptions Among Florida's Single Family Homeowners." Landscape and Urban Planning 3: 120-135.

Peguero, Anthony A. 2006. "Latino Disaster Vulnerability: The Dissemination of Hurricane Mitigation Information among Florida's Homeowners." Hispanic Journal of Behavior Science 28: 5-22.

Perry, Ronald W., and Majorie R. Greene. 1983. Citizen Response to Volcanic Eruptions: The Case of Mt. St. Helens. New York: Irvington Publishers.

PHEgov. 2011. "The National Disaster Medical System (NDMS)." Published December 15, 2011. Video, 1:29. https://www.youtube.com/watch?v=5Dky4vc5Q50.

Ruin, Isabelle, Cedar League, Mary Hayden, Barry Coldsmith, and Jeral Estupiñan. 2008. “Differential Social Vulnerability and Response to Hurricane Doly Across the US-Mexico Border." Quick response report, Natural Hazards Center. https://halshs.archivesouvertes.fr/halshs-00382708.

Solis, Daniel, Michael Thomas, and David Letson. 2010. "An Empirical Evaluation of the Determinants of Household Hurricane Evacuation Choice." Journal of Development and Agricultural Economics 2: 188-196.

Terpstra, Teun, and Jan M. Cutteling. 2008. "Households' Perceived Responsibilities in Flood Risk Management in the Netherlands." International Journal of Water Resources Development 24 (4): 555-565.

Terpstra, Teun, Michael K. Lindell, and Jan M. Cutteling. 2009. “Does Communicating (Flood) Risk Affect (Flood) Risk Perceptions? Results of a Quasi-Experimental Study." Risk Analysis 29 (8): 1141-1155.

Thiede, Brian C., and David L. Brown. 2013. "Hurricane Katrina: Who Stayed and Why?" Population Research and Policy Review 32 (6): $803-824$. Verroen, Stephan, Jan M. Gutteling, and Peter De Vries. 2013. “Enhancing Self-Protective Behavior: Efficacy Beliefs and Peer Feedback in Risk Communication." Risk Analysis 33 (7): 1252-1264.

Zucchino, David. 2008. “Evacuations are Ordered as IkeSstrengthens in Culf.” Los Angeles Times, Sept. 11, 2008.

http://articles.latimes.com/2008/sep/11/nation/na-ike11. 